\title{
Análise multitemporal das mudanças no uso e ocupação do Parque Estadual do Itacolomi (MG) através de técnicas de geoprocessamento
}

\author{
Multitemporal analysis of land use changes in the Itacolomi \\ State Park (MG) by geoprocessing techniques
}

Maria Augusta Gonçalves

Fujaco

Aluna de Doutorado no Programa de Pós-Graduação em Evolução Crustal e Recursos Naturais (DEGEO/UFOP)

E-mail: augusta@degeo.ufop.br

\section{Mariangela Garcia Praça Leite}

Professora do curso de Engenharia Geológica, Engenharia Ambiental e do Programa de Pós-Graduação em Evolução Crustal e Recursos Naturais

(DEGEO/UFOP)

E-mail:garcia@degeo.ufop.br

\section{Maria Cristina Teixeira} Braga Messias

Aluna de Doutorado no Programa de Pós-Graduação em Evolução Crustal e Recursos Naturais (DEGEO/UFOP)

Professora do Departamento de

Biodiversidade, Evolução e Meio Ambiente (DEBIO/UFOP)

E-mail: cristina@iceb.ufop.br

\section{Resumo}

Nos últimos quarenta anos, o Parque Estadual do Itacolomi (PEI), localizado na região de Ouro Preto, Minas Gerais, esteve sujeito a várias mudanças em seus padrões de uso e ocupação do solo. Essas mudanças foram registradas e quantificadas através de sensoriamento remoto e técnicas de geoprocessamento, com as quais se efetuou o mapeamento das transformações no uso e na ocupação da área durante essas quatro décadas. A fim de se avaliarem as mudanças no uso e ocupação, foram definidas as seguintes classes vegetacionais: Floresta Estacional Semidecidual, Campos Rupestres e Áreas Antropogênicas. Primeiramente, foram comparados os mapeamentos de uso da terra de 1966 e 1974, definidos como primeiro período de análise, depois, 1974 e 1986, considerados segundo período de análise; e, por último, o terceiro período de análise: 1986 e 2000. As mudanças que ocorreram no PEI foram predominantemente de origem antrópica, com uma maior intensidade nos anos setenta. Como resultado do abandono dessas atividades e, também, devido a um maior monitoramento e controle das ações antrópicas efetuadas no PEI nas décadas seguintes, as áreas abandonadas foram pouco a pouco sendo ocupadas por plantas pioneiras como as candeias, recuperando a região.

Palavras-chave: Mudança do uso da terra, geoprocessamento, sistema de informação geográfica, análise multitemporal, Parque Itacolomi, Minas Gerais.

\begin{abstract}
Over the past forty years, Itacolomi State Park (ISP), located in the region of Ouro Preto/Minas Gerais, has been subject to several changes in its patterns of land use and occupation. These changes were recorded and quantified using remote sensing and GIS techniques, which allowed for the construction of four land use maps, representing the changes in the area during the last four decades. In order to evaluate these changes, the following classes of vegetation were defined: Seasonal Semideciduous Forest, Rocky outcrops and Anthropogenic Areas. First, land use maps from 1966 and 1974 were compared, defining the first period of analysis; then, 1974 and 1986 maps were considered in the second period of analysis, and finally the third period of analysis used 1986 and 2000 maps. The changes that occurred in ISP were predominantly of anthropogenic origin, with greater intensity in the
\end{abstract}


seventies. As a result of the abandonment of these activities and also due to greater monitoring and control of human actions performed at ISP during the following decades, the abandoned areas are gradually being occupied by native plants such as "candeia" (Eremanthus $s p)$, rehabilitating the region.

Keywords: Land use change, geoprocessing, geographic information system, multitemporal analysis, Itacolomi Park, Brazil.

\section{Introdução}

A proteção do meio ambiente tornou-se um dos grandes temas da humanidade nessas últimas décadas. Em especial, a proteção e a conservação da biodiversidade vêm recebendo uma prioridade crescente, sobretudo pelos governos e organizações não-governamentais de todo o mundo. Ao mesmo tempo em que as questões ambientais passaram a fazer parte das preocupações da sociedade brasileira (confrontada com a crescente escassez de água, degradação do solo, poluição atmosférica, etc), o governo, sobretudo a partir da década de 1970, também começou a estabelecer instituições, mecanismos e legislações destinadas à conservação ambiental. Apesar do ordenamento jurídico brasileiro, no que diz respeito à proteção ambiental, ser relativamente antigo, com as primeiras referências ao meio ambiente encontradas na Carta Régia de 1797 (Silva Filho, 2002), foi somente em 1981, com a lei 6.938, no seu artigo IX, que a criação de áreas de Proteção Ambiental passou a ser um dos instrumentos de Política Nacional do Meio Ambiente. Mesmo assim, somente em 18 de julho de 2000, foi criado o Sistema Nacional de Unidades de Conservação - SNUC através da Lei $n^{\circ} 9.985 / 00$. Com o objetivo de estabelecer critérios e normas para a criação, implantação e gestão das unidades de Conservação, a lei dividiu as unidades de conservação integrantes em dois grupos, com características específicas: Unidades de Proteção Integral e Unidades de
Uso Sustentável. No primeiro grupo, se encontram os Parques, como o Parque Estadual do Itacolomi. O objetivo básico das Unidades de Proteção Integral é preservar a natureza, sendo admitido apenas o uso indireto dos seus recursos naturais, com raras exceções, definidas na lei. O Parque, como Unidade de Conservação, tem como objetivo básico a preservação de ecossistemas naturais de grande relevância ecológica e beleza cênica, possibilitando a realização de pesquisas científicas e o desenvolvimento de atividades de educação e interpretação ambiental, de recreação em contato com a natureza e de turismo ecológico. Segundo a lei, a área de um Parque é de posse e domínio públicos, sendo que as propriedades particulares incluídas em seus limites, quando da sua fundação, são desapropriadas. Já a visitação pública é sujeita às normas e restrições estabelecidas no Plano de Manejo da unidade e às normas estabelecidas pelo órgão responsável por sua administração.

Apesar de atualmente a legislação ambiental brasileira ser considerada uma das mais completas do mundo (Freire, 2005), muitos de seus instrumentos têm se revelado inadequados para a proteção da natureza. A explicação mais corrente é a de que faltam recursos financeiros, humanos e, conseqüentemente, fiscalização (Diegues, 2000).

\section{Geoprocessamento e estudos ambientais}

O geoprocessamento é uma ferramenta muito poderosa, sendo capaz, não só de armazenar, quantificar e manipular dados georeferenciados, como também cruzar esses dados e tratá-los estatisticamente. A utilização de técnicas de geoprocessamento, conjuntamente com o sensoriamento remoto e de Sistemas de Informação Geográfica (SIG) tem permitido a realização de inúmeros trabalhos nos vários campos da ciência, nomeadamente na área ambiental. Nessa área, podemos citar diversos trabalhos que exploram diferentes objetivos, como o uso e a ocupação do solo em escalas multitemporais, diagnóstico de áreas susceptíveis à erosão, caracterização e análise de bacias hidrográficas e na utilização dos modelos digitais do terreno em análises geomorfológicas (Carvalho et al., 2004; Farinasso et al., 2006; Scheer \& Rocha, 2006; Oralieta et al., 2008; Maeda et al., 2008). No caso de estudos das transformações do uso da terra, a utilização dessas técnicas é particularmente apropriada, principalmente por permitir a elaboração de uma base georreferenciada, que facilita a representação e a análise do espaço de forma dinâmica. Além disso, a avaliação dos mapas gerados possibilita o acompanhamento temporal das transformações ocorridas em um determinado intervalo de tempo, na área em foco. É nessa vertente de análise de dinâmica do uso e ocupação da terra que o SIG tem sido amplamente utilizado em diversos trabalhos como a evolução em áreas urbanas (Tian et al., 2005; Baskent \& Kadiogullari, 2007) e na deteç̧ão de mudanças na vegetação, quer em áreas agrícolas (Li et al., 2004; Tottrup et al., 2004; Wardlow et al., 2008), quer em sistemas naturais (Volcani et al., 2005, Phillips et al., 2008; Karlsen et al., 2008). Esse trabalho segue essa linha de pesquisa e teve como principal objetivo utilizar técnicas de geoprocessamento para analisar e quantificar o uso e ocupação do solo do Parque Estadual do Itacolomi desde 1966 a 2000, de forma a servir de subsídio para a avaliação da eficiência da legislação ambiental no que tange à proteção do meio ambiente em uma Unidade de Conservação.

\section{Materiais e métodos}

\section{1 Área de estudo}

O Parque Estadual do Itacolomi (PEI) encontra-se inserido nos municípios de Ouro Preto e Mariana, Estado de Minas Gerais, entre os meridianos $43^{\circ} 32^{\prime} 30^{\prime \prime}$ e $43^{\circ} 22^{\prime} 30^{\prime \prime}$ de longitude oeste e os paralelos $20^{\circ} 22^{\prime} 30$ ”'e $20^{\circ} 30^{\prime} 00^{\prime}$ de latitude sul (Figura 1).

Essa Unidade de Conservação (UC) foi criada pela lei estadual 4.495 
Maria Augusta Gonçalves Fujaco et al.

de 14 de Junho de 1967. Localiza-se na terminação sul da serra do Espinhaço, abrangendo uma área de aproximadamente $7.200 \mathrm{~km}^{2}$. A serra do Espinhaço pertence ao chamado planalto Atlântico e estende-se pelos Estados da Bahia e Minas Gerais. É considerada reserva mundial da biosfera, por ser uma das regiões mais ricas do planeta, pela sua grande diversidade biológica. Os traços regionais do relevo, acidentado com vertentes bem íngremes e vales profundos e encaixados, mostram uma clara dependência com a geologia local, que controla a conformação em duas direções preferenciais de serras e drenagens (Varajão, 1988). O principal elemento da paisagem é sem dúvida a serra do Itacolomi, com altitudes oscilando entre $700 \mathrm{e}$ 1772m. A cobertura vegetal, pertencente aos domínios Mata Atlântica e Cerrado, apresenta ampla diversificação fisionômica, devido à elevada heterogeneidade ambiental, sendo que os principais tipos vegetacionais encontrados no parque são as florestas estacionais semideciduais submontana, os habitats mésicos (brejos), os campos rupestres, as formações monodominantes de Eremanthus spp. (candeiais), além dos eucaliptais. Nos vales, nas drenagens e nas encostas mais baixas, a vegetação é mais densa que nas áreas restantes, variando de uma mata rala, constituída principalmente por espécies arbustivas para uma mata de galeria de maior porte. Já a superfície cimeira é dominada por espécies herbáceas. A geologia local do PEI é representada pelas rochas metassedimentares clásticas dos Supergrupos Rio das Velhas, Minas (Grupo Piracicaba) e Grupo Itacolomi, cujo empilhamento encontra-se controlado por falhas de cavalgamento (Gloeckner, 1881 in Castañeda, 1993). Predominantes na área, os quartzitos do Grupo Itacolomi foram divididos por Ferreira e Lazarin (1993) em: quartzitos inferiores e superiores, separados por xistos do Supergrupo Rio das Velhas. Encontram-se também na região rochas intrusivas - metabásicas (Barbosa, 1959); depósitos elúvio-coluvionares, representados principalmente pela canga (Ferreira \& Lazarin, 1993) e depósitos recentes associados aos alúvios do córrego Prazeres e do rio Maynart.

\section{Histórico de ocupação da região}

Desde sua ocupação colonial até aos dias de hoje, a área que hoje corresponde ao PEI tem tido participação ativa na vida das duas cidades históricas localizadas em suas redondezas, Ouro Preto e Mariana (Figura 1). Relata Santos Maia (1970), em "Uma Breve História de Vila Rica e um Pequeno Roteiro de Ouro Preto”, que a própria fundação de Ouro Preto está relacionada com o Pico Itacolomi:

“... foi nessa ocasião, fins do século XVII, que uma Bandeira Paulista, chefiada pelo bandeirante Antônio Dias de Oliveira chegou a esta região. Região de elevada altitude, vivia o céu sempre brumado ... Os bandeirantes apenas possuíam, como ponto de referência, o marco do magnífico do Itacolomi...."

A região já foi palco de várias atividades antrópicas, a maioria destas de importância econômica para a comunidade das duas cidades. No final do século XVI, foram descobertas as primeiras ocorrências de depósitos minerais na região. Foi nessa época que o bandeirante Manoel Garcia encontrou ouro nos córregos que passam nas proximidades do Pico do Itacolomi. Os bandeirantes descobriram, no córrego do Tripuí, pedras escuras e pesadas, o chamado “ouro preto” (Germani, 2002). Nos séculos XVIII e XIX, com o declínio da exploração do ouro, a área do parque teve papel fundamental na economia da região. Com o início das grandes plantações de chá (Camellia sinensis), surgiram grandes fazendas, como, por exemplo, a Fazenda São José do Manso, a Fazenda de Cintra e a Fazenda do Cibrão, constituindo a principal atividade econômica dessa época. Conta-se que o chá aí produzido, um chá preto de excelente qualidade, era inclusive exportado para a Europa, especialmente para a Inglaterra. O chá Edelweiss, um dos mais famosos, foi produzido na Fazenda do Manso até a década de cinqüenta. Com o final das exportações de chá, a região passou a ser utilizada por grandes empresas como a Alcan (atual Novelis),

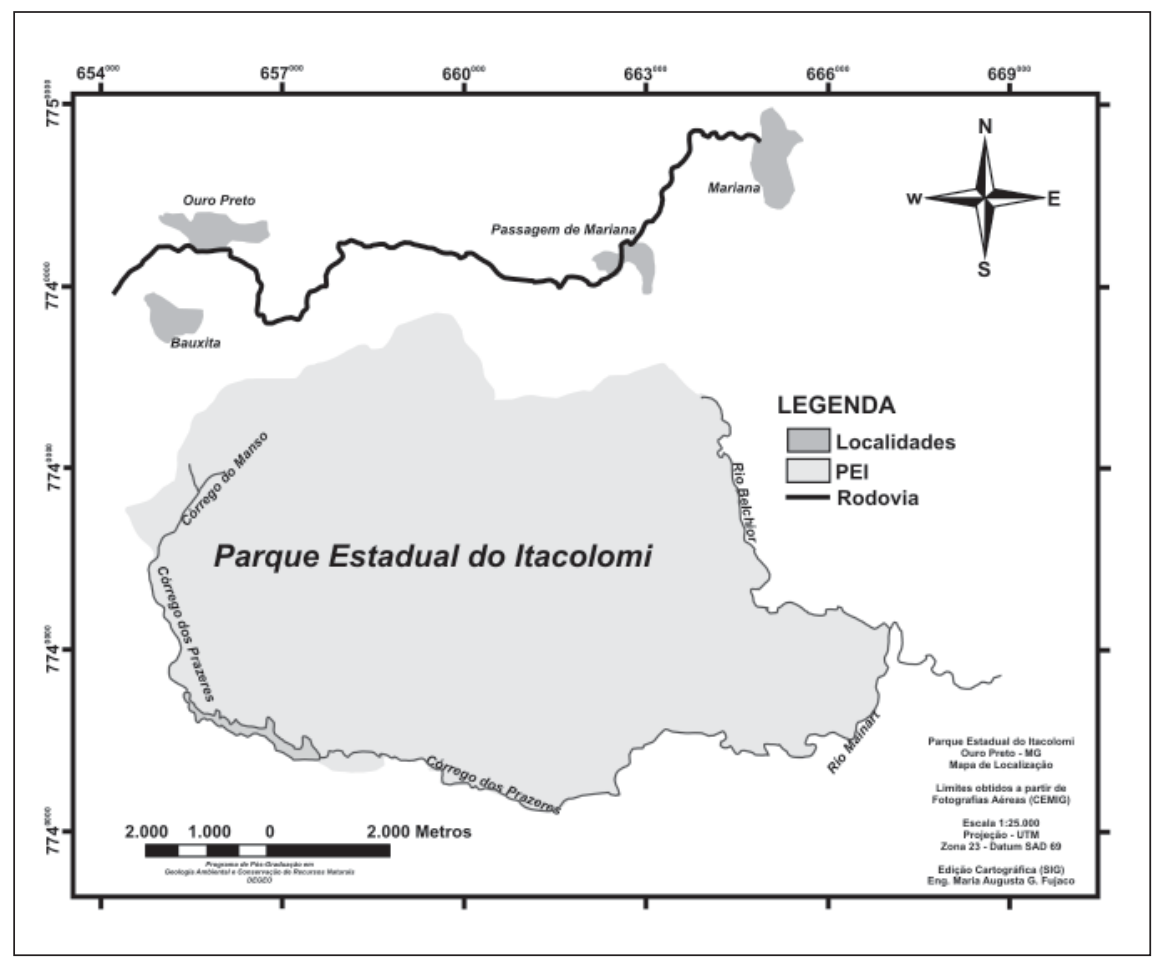

Figura 1 - Mapa de Localização do Parque Estadual do Itacolomi. 
a Companhia Minas de Passagem e a Companhia Queiroz Jr., que desmataram uma grande parte da área para plantio de eucalipto, a ser utilizado na produção de carvão vegetal para os altos-fornos. Atualmente, o fato mais preocupante é a ocupação desordenada que ocorre na chamada zona de amortecimento do PEI, com a urbanização do bairro Pocinho, em Ouro Preto, e do distrito de Passagem de Mariana. Nestes casos, os empreendimentos urbanos não distam $1 \mathrm{~km}$ do limite do PEI, cujo crescimento desordenado dos últimos anos mostra uma tendência de expansão. Associadas a essa invasão urbana, existem ainda atividades ilegais como a extração de lenha para uso doméstico, caça e pesca e a ocorrência de incêndios descontrolados (quase sempre criminosos).

\subsection{Materiais utilizados}

Na procura de dados históricos sobre a economia e sobre as atividades desenvolvidas nos municípios de Mariana e Ouro Preto, durante os últimos sessenta anos, foram feitas pesquisas em documentos disponíveis no Arquivo Nacional, Museus e Universidade Federal de Ouro Preto. Através dessa coleta de informações, foram adquiridos os seguintes materiais, que atualmente fazem parte do acervo da UFOP:

- Mapa topográfico - escala 1:25.000.

- Mapa Geológico - escala 1:25.000.

- Fotografias aéreas de 1966 - 1:60.000 (USAF - projeto 6332); Fotografias aéreas de 1974 (FAB/IBGE - projeto 1) - 1:25.000; Fotografias aéreas de 1986 - 1:30.000 (CEMIG).

- Imagem de satélite Ikonos de 2000 - 1:25.000

\subsection{Procedimentos metodológicos Definição das classes de uso e ocupação}

A fim de se avaliarem as mudanças no uso e na ocupação, foram definidas as seguintes classes vegetacionais: Floresta Estacional Semidecidual, Campos Rupestres e Áreas Antropogênicas. Para a definição dessas classes, foram realizadas várias saídas de campo para os respectivos levantamentos florísticos, os quais definiram os grupos vegetacionais. Esse levantamento está disponível na listagem da flora do Parque Estadual do Itacolomi (IEF, 2006).

\section{Mapeamento do uso e ocupação do solo nas fotografias aéreas e imagem Ikonos}

Numa primeira fase, foi realizada a fotointerpretaçao das fotografias aéreas com o auxilio de um estereoscópico de espelhos, na qual foram definidas as diversas classes de uso e ocupação. Após a fotointerpretação em laboratório, as fotografias aéreas foram georreferenciadas com o software Arcview ${ }^{\circledR}$ 9.2 e inseridas em um ambiente SIG (sistema de informação geográfica). No caso da imagem Ikonos, o mapeamento das diferentes classes foi realizado diretamente sobre a imagem.

\section{Análise multitemporal}

Primeiramente, foram comparados os mapeamentos resultantes da fotointerpretação do uso da terra de 1966 e 1974, definidos como primeiro período de análise. Depois, 1974 e 1986, considerados segundo período de análise; e, por último, o terceiro período de análise: 1986 e 2000. Os resultados gerados, nessa etapa da pesquisa, foram tabelados, definindo-se a área (em percentual) de variação de cada classe de uso e ocupação predefinida.

\section{Resultados e discussão}

O mapa de uso e de ocupação do ano de 1966 (Figura 2) reflete as atividades humanas desencadeadas até meados do século XX. Na Figura 2, verifica-se que a Floresta Semidecidual ocupa a maior área, cerca de 50\%, o Campo Rupestre ocupa uma área de $40 \%$ e as Atividades Antropogênicas ocupavam uma área de 10\%. Estas últimas estão representadas por resquícios das plantações de chá, concentradas na região do Manso (atual sede do parque, localizada em sua porção noroeste).

Já o mapa de 1974 (Figura 3) reflete as atividades do início dos anos setenta, quando as indústrias locais começaram a utilizar a área do parque para produção de carvão para abastecer os fornos das siderúrgicas. Como conseqüência, parte da vegetação natural foi destruída e substituída por plantações de Eucaliptus sp. na parte sudoeste do PEI. Ainda durante essa década, as áreas abandonadas das plantações de chá mostram a colonização por Eremanthus erythropappus, uma planta pioneira, nativa dessa região, conhecida pelo nome vulgar de “candeia”, originando grandes populações dessa espécie na região da antiga Fazenda do Manso.

Apesar da criação do Parque ter ocorrido em 1967, este só começou a funcionar efetivamente como Unidade de Conservação no final dos anos setenta. Devido a isso, no decorrer desses anos, ainda existiram atividades ilegais realizadas no PEI por habitantes locais, relacionadas principalmente com a extração ilegal de madeira. No mapa de 1986 (Figura 4), podese notar que as áreas campestres diminuíram ainda mais, fato que pode ser explicado por essas atividades antropogênicas, desenvolvidas no entorno da área do parque, e pelas suas conseqüências, como incêndios provocados pela queima da vegetação natural para aumento das áreas de pastagem e a retirada de plantas nativas. A efetivação do PEI teve um papel importante nesse período, com o início das atividades de proteção ambientais. Esse fato está claramente demonstrado nos dados de 1986, onde de verificou uma recuperação significativa das áreas com atividades antropogênicas delimitadas no ano de 1974 (Figura 3), especialmente as localizadas no entorno da sede do parque (Fazenda do Manso). 
Maria Augusta Gonçalves Fujaco et al.

No mapa de uso e ocupação do ano 2000 (Figura 5), a Floresta Semidecidual mantém-se quase inalterável (aproximadamente 56\%), enquanto que os Campos Rupestres tiveram uma recuperação de 36\% em 1986 para 44\% (Figura 6). O aumento das áreas naturais é uma conseqüência das atividades conservacionistas desenvolvidas pelo Instituto Estadual das Florestas (IEF), o qual tem desenvolvido programas antifogo durante os meses mais críticos (abril a setembro). Concomitantemente, o IEF está implementando um plano de manejo, visando a conservar e proteger essas áreas conjuntamente com a comunidade ao redor do parque. Paralelamente, o órgão mantém planos educacionais com várias escolas, nos quais promovem passeios educativos ao longo das diversas trilhas criadas para esse propósito e investe em palestras educacionais ao longo do ano com o objetivo de integrar a comunidade com o parque e a sensibilizá-la no sentido de respeitar e valorizar este precioso bem natural.

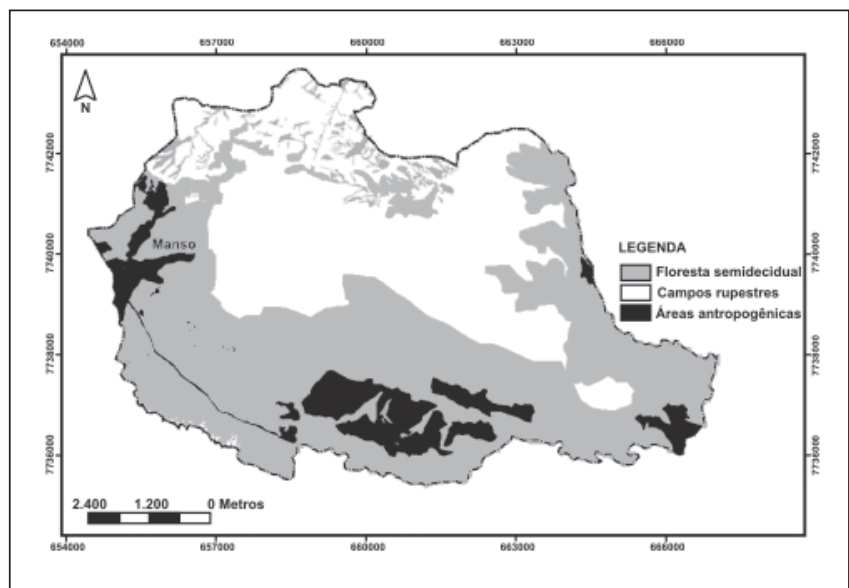

Figura 2 - Mapa de uso e de ocupação da área do PEI de 1966. Destaque para a área do Manso, mancha de atividades antropogênicas na porção noroeste do parque.

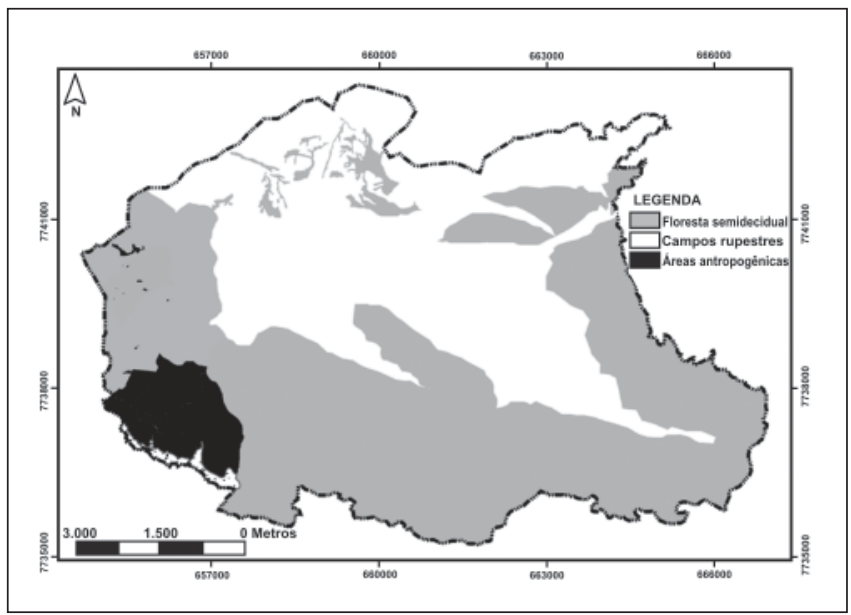

Figura 4 - Mapa de uso e de ocupação da área do PEI de 1986.

\section{Conclusões}

Não há dúvida que a paisagem é controlada por fatores físicos e biológicos. No entanto, ao quantificar o uso e a ocupação do Parque Estadual do Itacolomi (PEI), ao longo de três décadas, verificou-se que as unidades de paisagem também podem ser controladas por ações antropogênicas. A redução e o aumento da área de cada fitofisionomia que caracteriza o PEI foram conseqüências de uma situação social e econômica regional que prevaleceu em cada uma das últimas décadas. No último século, o PEI foi utilizado como uma fonte econômica por várias atividades desenvolvidas em sua área, sendo as mais marcantes a produção de chá e a de carvão. Durante a ocorrência dessas atividades, não houve nenhum projeto de sustentabilidade nessas áreas, sendo que as referidas plantações (chá e eucalipto) foram abandonadas, sem qualquer iniciativa de recuperação. Lentamente, a vegetação nativa (nomeadamente as plantas pioneiras) foi ocupando os espaços deixados (Figuras 2, 3, 4 e 5).

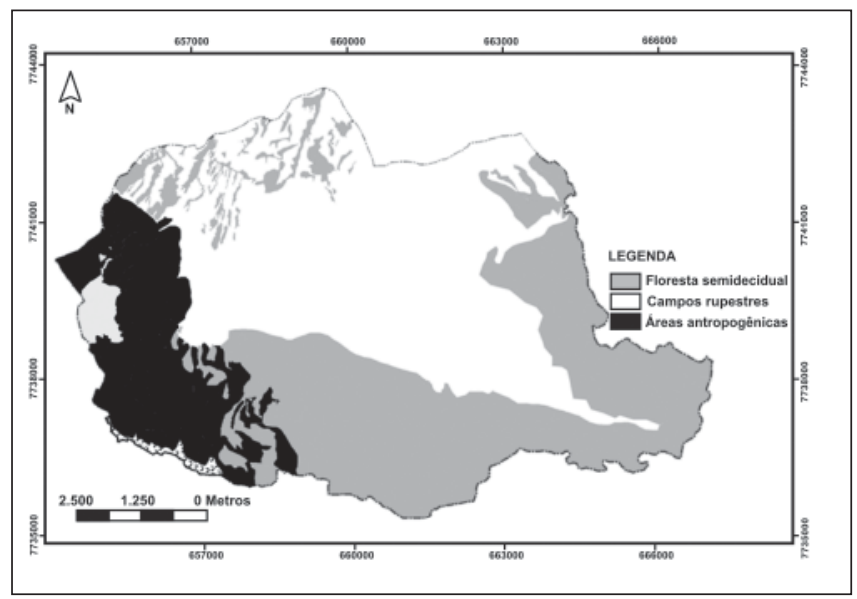

Figura 3 - Mapa de uso e de ocupação da área do PEI de 1974.

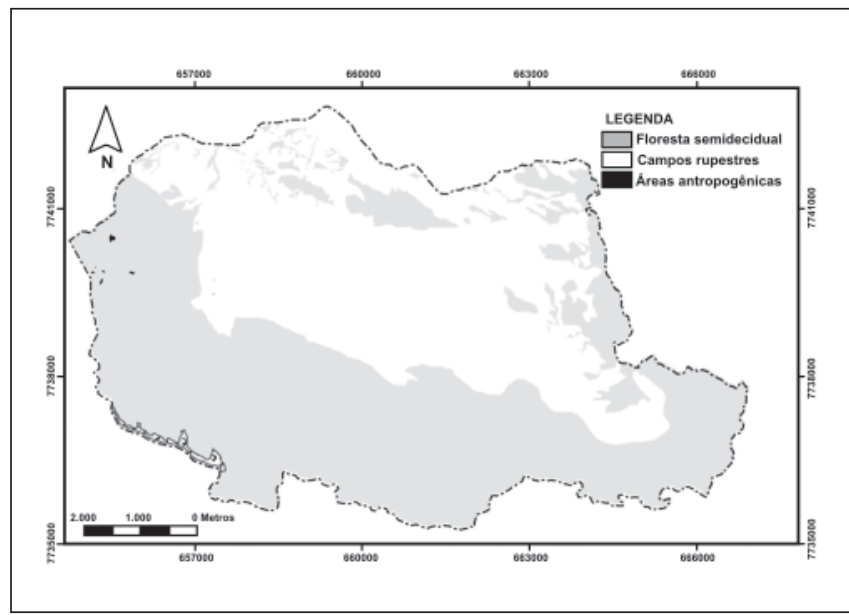

Figura 5 - Mapa de uso e de ocupação da área do PEI de 2000. 
Apesar de a criação do parque ter ocorrido oficialmente em 1967, somente nas imagens de 1986 é que se pode perceber uma redução efetiva das áreas antropizadas e a recuperação das porções abandonadas, ou seja, por mais de uma década após a sanção da lei de criação do parque, este ainda sofreu com os impactos ambientais oriundos de atividades antropogênicas. Os resultados mostram que a simples criação de Unidades de Conservação não é suficiente para garantir a preservação dos recursos naturais, sendo necessárias ações efetivas por parte do poder público. No caso do PEI, a redução dessas atividades antropogênicas só ocorreu devido ao monitoramento rigoroso dessa área por parte do Instituto Estadual das Florestas (IEF), associado ao desenvolvido programas antifogo durante os meses mais críticos (abril a setembro). Paralelamente, o parque criou programas educacionais, que promovem passeios educativos e palestras educacionais ao longo do ano, buscando sensibilizar a comunidade no que tange à preservação do meio ambiente. A implementação dessas ações ao longo das últimas décadas já surtiu efeito, culminando na redução quase total das áreas degradadas e na recuperação das porções abandonadas, hoje em franco processo de revegetação, com o surgimento de matas de candeia (Eremanthus sp).

\section{Agradecimentos}

Os autores gostariam de agradecer o apoio do Instituto Estadual de Florestas (IEF); em especial a Alberto V. Matos, Juarez T. Basílio e a todos os funcionários do Parque Estadual do Itacolomi pelo seu suporte logístico.

\section{Referências bibliográficas}

BARBOSA, A. L. M. Série Itacolomi. Pub. Esp. DPM.01, Rio de Janeiro. 20 - 22. 1959.

BASKENT, E. Z., KADIOGULLARI, A. Spatial and temporal dynamics of land use pattern in Turkey: A case study in Inegol. Landscape and Urban Planning. v. 81, p. 316-327, 2007.

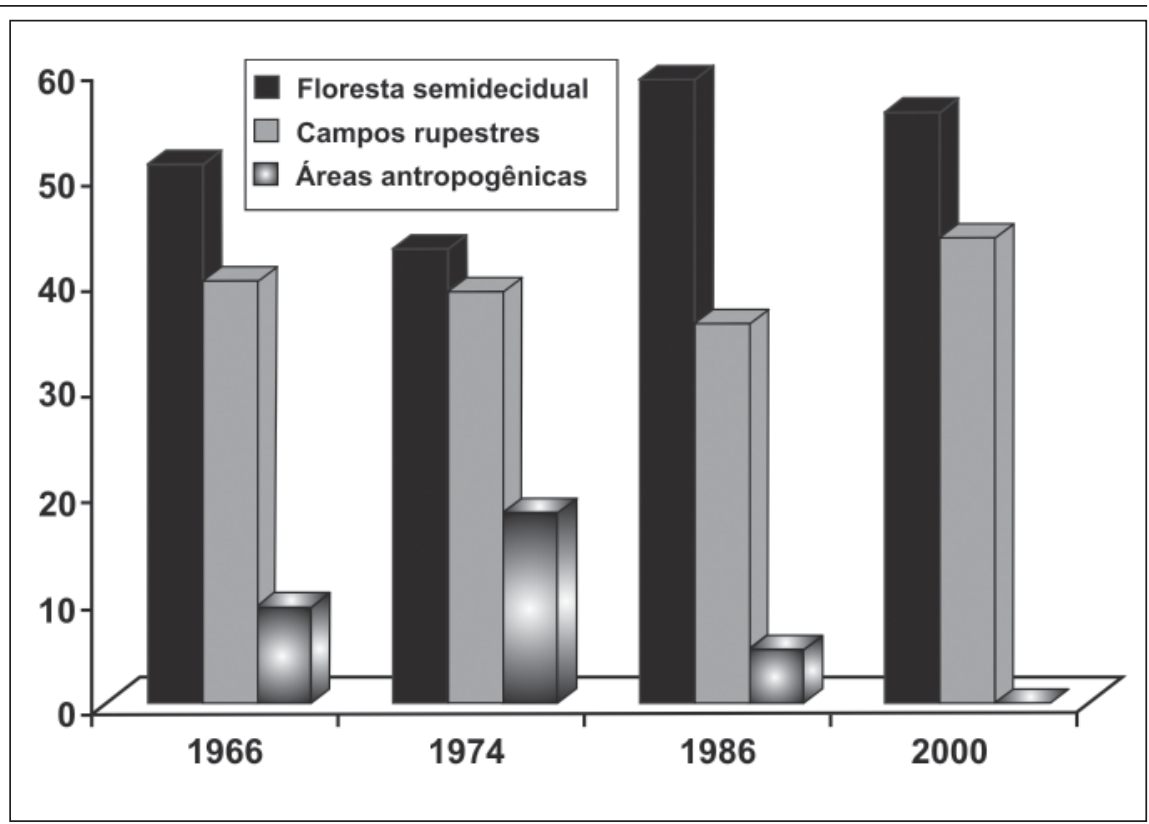

Figura 6 - Histograma mostrando a variação percentual das diversas classes de uso e de ocupação na área do PEI no período de 1966 a 2000.

CARVALHO, T. M., LATRUBESSE, E. M. Aplicação de Modelos Digitais de Terreno (MDT) em análises macrogeomorfológicas: o caso da bacia hidrográfica do Araguaia. Revista Brasileira de Geomorfologia, v.1. p.85-93, 2004.

CASTANEDA, C. Caracterização geológica e geomorfológica do Parque Estadual de Itacolomi. Projeto Itacolomi, Convênio IEF/UFOP/BIRD. 1993. 36p. (Relatório de Projeto).

DIEGUES, A. C. Etnoconservação: novos rumos para a conservação da natureza. São Paulo: Hucitec, 2000. 290p.

FARINASSO, M., JÚNIOR, O. A.C., GUIMARÃES, R. A. T., GOMES, R. A. T., RAMOS, V. M. Avaliação qualitativa do potencial de erosão laminar em grandes áreas por meio da EUPS - Equação Universal de Perdas de Solo, utilizando novas metodologias em SIG para o cálculo dos seus fatores na região do Alto Parnaíba - PI - MA. Revista Brasileira de Geomorfologia. v. 2, p. 73-85, 2006.

FERREIRA, A. F., LAZARIN, H. A. Caracterização litoestrutural e geomorfológica da região do pico do Itacolomi, Ouro Preto. Ouro Preto: DEGEO/UFOP, 1993. 54p. (Monografia de Graduação em Engenharia Geológica).

FREIRE, G. D. Ecos de um projeto de educação ambiental. Brasília: Universidade Católica de Brasília, 2005. 84 p.

FUJACO, M. A. G. Influência dos diferentes tipos de substrato e geomorfologia na distribuição espacial e arquitetônica do gênero Ermanthus sp, no Parque Estadual do Itacolomi, Ouro Preto/MG. Ouro Preto: Universidade Federal de Ouro Preto, 2007. 111p. (Dissertação de Mestrado).

GERMANI, D. J. A Mineração no Brasil. Rio de Janeiro: Centro de Gestão e Estudos Estratégicos, Ciência, Tecnologia e Inovação, 2002. (Relatório Final).

KARLSEN, S. R., TOLVANEN, A., KUBIN, E., POIKOLAINEN, J., HøGDA, K. A., JOHANSEN, B., DANKS, F.S., ASPHOLM, P., WIELGOLASKI, F. E., MAKAROVA, O. MODIS-NDVI-based mapping of the length of the growing season in northern Fennoscandia. International Journal of Applied Earth observation and Geoinformation, v. 10, p. 253-266, 2008.

LI, J., LEWISA, J., ROWLANDB, J., G. TAPPANB TIESZENC, L. L. Evaluation of land performance in Senegal using multi-temporal NDVI and rainfall series. Journal of Arid Environments. v. 59, p.463-480, 2004.

MAEDA, E. E., ARCOVERDE, G. F. B.., FORMAGGIO, A. R., SHIMABUKURO, Y. E. Evaluation of the potentiality of wfi/cbers-3 sensor data for land use and land cover classification. Revista Brasileira de Geomorfologia. v. 60, n. 1, p. 70-87, 2008. 
Maria Augusta Gonçalves Fujaco et al.

ORALIETA, J. R., VALLE, F. L. R., TELLO, E. Preserving and destroying soils, transforming landscapes: soils and land-use changes in the Valle's County (Catalunya, Spain) 1853-2004. Land Use Policy. v. 25, p. 474-484, 2008.

PHILLIPS, L. B., HANSEN, A. J., FLATHER, C. H. Evaluating the species energy relationship with the energy. Remote Sensing of Environment, v. 112 , p. 4381-4392, 2008.

IEF (Instituto Estadual de Florestas) Plano de manejo do Parque Estadual do Itacolomi. Fundação Biodiversitas e Universidade Federal de Ouro Preto, 2006.

SANTOS MAIA, A. E. Uma breve história de Vila Rica e um pequeno roteiro de Ouro Preto. Cadernos de Apontamentos, n.2, 1970. 56p.
SCHEER, M. A. P. S., ROCHA, J. V. Detecção de mudanças no uso da terra no município de sertãozinho (SP) por meio de técnicas de geoprocessamento, 1981 - 2001. Revista Brasileira de Cartografia, v. 28, n. 2, agosto de 2006.

SILVA FILHO, J. M. Controle ambiental na mineração. Ietec-Instituto de Educação Tecnológica, 2002. 71p.

TIAN, G., LIU, J., XIE, Y., YANG, Z., ZHUANG, D., NIU, Z. Analysis of spatio-temporal dynamic pattern and driving forces of urban land in China in 1990 susing TM images and GIS. Cities. v. 22, n. 6, p. 400-410, 2005.

TOTTRUP, C., RASMUSSEN, M. S. Mapping long-term changes in savannah crop productivity in Senegal through trend analysis of time series of remote sensing data. Agriculture, Ecosystems and Environment, v. 103, p. 545-560, 2004.

VARAJAO, A. F. D. C., ROCHA, L. A., BOULAGÉ, B., MOREIRA, A. P. A. Colluvial features of clayey deposits of the Moeda Syncline, Quadrilátero Ferrífero, Minas Gerais, Brazil. In: LAK, 16. Bayreuth: Terra Nostra, 1998. v. 5, p. 164-164.

VOLCANI, A., KARNIELI, A., SVORAV, T. The use of remote sensing and GIS for spatiotemporal analysis of the physiological state of a semi-arid forest with respect to drought years. Forest Ecology and Management, v. 215, p. 239-250, 2005.

WARDLOW, B. D., EGBERT, S.L. Large-area crop mapping using time-series MODIS 250 m NDVI data: An assessment for the U.S. Central Great Plains. Remote Sensing of Environment. v. 112, p. 1096-1116, 2008.

Artigo recebido em 08/12/2009 e aprovado em 09/07/2010.

\section{Descubra as muitas informações da: Geologia, Mineração,} Metalurgia \& Materiais e Engenharia Civil.
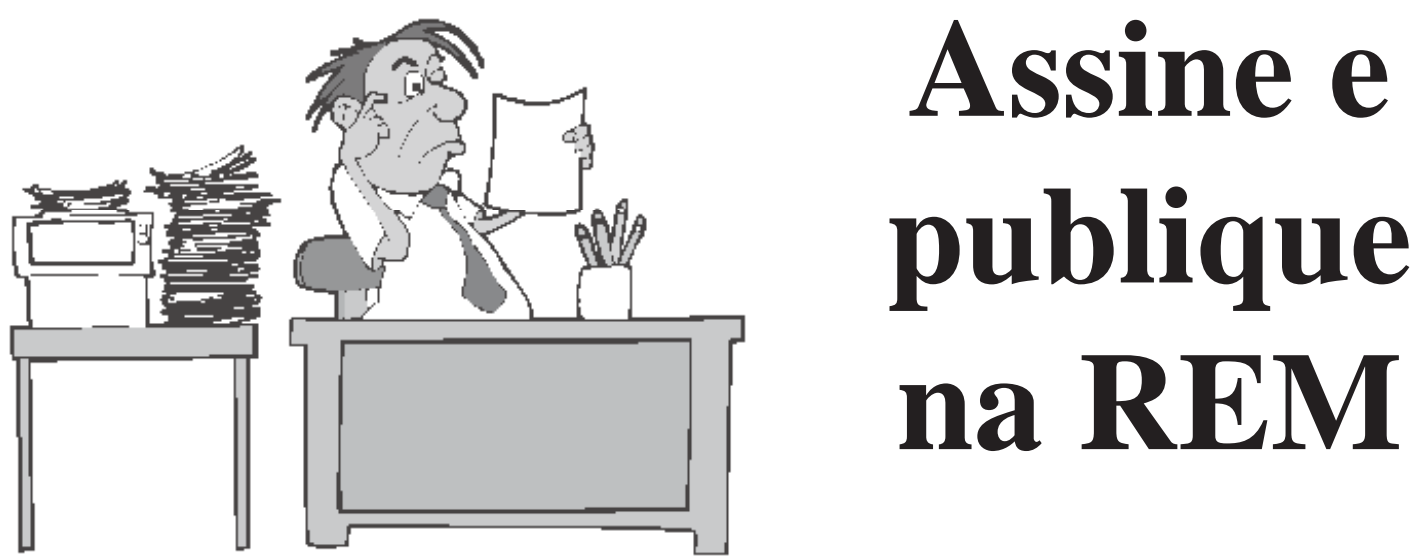

Conheça o nosso site: WWW.rem.com.br 